\title{
The Ten Commandments for Managing Value-at-Risk Under the Basel II Accord*
}

\author{
Juan-Ángel Jiménez-Martín \\ Department of Quantitative Economics \\ Complutense University of Madrid
}

Michael McAleer

Department of Quantitative Economics

Complutense University of Madrid

\section{Teodosio Pérez-Amaral}

Department of Quantitative Economics

Complutense University of Madrid

March 2009

* For financial support, the first author wishes to thank the Secretaría de Estado de Universidades of Spain through project SEJ206-14354 and Complutense University through project UCM-940063, the second author is grateful to the Australian Research Council, and the third author wishes to thank the Secretaría de Estado de Universidades of Spain through project ECO2008-06091/ECON.

Corresponding author: Juan-Ángel Jiménez-Martín (juanangel@ccee.ucm.es). 


\begin{abstract}
Under the Basel II Accord, banks and other Authorized Deposit-taking Institutions (ADIs) are required to communicate their daily market risk estimates to the relevant national monetary authority at the beginning of each trading day, using one of a variety of Value-at-Risk (VaR) models to measure risk. The purpose of this paper is to provide a simple explanation and a set of prescriptions for managing VaR under the Basel II Accord. The commandments deal with understanding the Basel II colours, understanding the risk model before choosing, varying the choice of risk model, avoiding the green zone and being willing to violate, incurring large violations, stopping before the red zone, avoiding frequent violations, avoiding the estimation of large portfolios, aggregating portfolios into a single index, and interpreting commandments sensibly as guidelines.
\end{abstract}

Key words and phrases: Financial portfolios, daily capital charges, frequency of violations, magnitude of violations, optimizing strategy, risk forecasts, value-at-risk, green zone, red zone.

JEL Classifications: G32, G11, G17. 
Jack Sparrow: "The only rules that really matter are these: what a man can do and what a man can't do."

\section{Pirates of the Caribbean: Curse of the Black Pearl}

Elizabeth: "You're pirates. Hang the code, and hang the rules. They're more like guidelines anyway."

\section{Pirates of the Caribbean: Curse of the Black Pearl}

Jack Sparrow: "I thought you were supposed to keep to the code."

Mr. Gibbs: "We figured they were more actual guidelines."

Pirates of the Caribbean: Curse of the Black Pearl

\section{Introduction}

Value-at-Risk (VaR) may be defined as "a worst case scenario on a typical day", and hence is concerned with unlikely (or possibly extreme) events. Under the Basel II Accord for market risk involving stocks and bonds (see Basel Committee on Banking Supervision (1988), (1995), (1996) for further details), banks and other Authorized Deposit-taking Institutions (ADIs) are required to communicate their daily market risk estimates to the relevant national monetary authority at the beginning of each trading day, using one of a variety of VaR models to measure risk (see Jorion (2000)).

A violation is said to occur when the negative returns exceed the VaR forecast at time $t$, such that actual losses on a portfolio are worse than had been predicted. In the context of the Basel II Accord, the optimization problem facing ADIs, with the number of violations and accurate forecasts of $\mathrm{VaR}$ as decision variables (see, for example, McAleer (2009) and McAleer, Jiménez-Martin and Peréz-Amaral (2009) for alternative strategies to endogenize the number of violations), is as follows:

$$
\underset{\{k, \mathrm{VAR}\}}{\operatorname{Minimize}} D C C_{t}=\sup \left\{-(3+k) \overline{\mathrm{VaR}}_{60},-\mathrm{VaR}_{t-1}\right\}
$$

where the minimization problem is defined in terms of

$D C C=$ daily capital charges, which is the higher of $-(3+k) \overline{\mathrm{VaR}}_{60}$ and $-\mathrm{VaR}_{t-1}$, $V A R_{t}=$ Value-at-Risk for day $t$, 
$V A R_{t}=\hat{Y}_{t}-z_{t} \cdot \hat{\sigma}_{t}$

$\overline{\mathrm{VaR}}_{60}=$ mean $\mathrm{VaR}$ over the previous 60 working days,

$\hat{Y}_{t}=$ estimated return at time t,

$z_{t}=1 \%$ (negative) critical value of the distribution of returns at time $t$,

$\hat{\sigma}_{t}=$ estimated risk (or square root of volatility) at time $t$,

$0 \leq k \leq 1$ is the Basel II violation penalty (see Table 1 ).

Investors can choose the financial assets in constructing a portfolio, but they cannot control the daily return of the portfolio. However, they can control daily capital charges by a judicious choice of $\hat{\sigma}_{t}$, which will affect $\mathrm{VaR}$ and the value of $k$ arising from the violation penalty.

According to Table 1, the value of $k$ can be determined exogenously or endogenously according to the penalty zones. The penalties arising from being colour coded are important because higher (lower) absolute estimates of $\mathrm{VaR}$ will tend to increase (decrease) daily capital charges, with a resulting lower (higher) value of $k$. ADIs that stray into the red zone can be given the ultimate penalty, namely a temporary or permanent suspension from trading activities.

\section{The Ten Commandments}

This section presents ten commandments that are intended to assist in managing VaR for market risk when the number of violations, and hence the value of $k$, can be exogenous or endogenous. 
Table 1: Basel Accord Penalty Zones

\begin{tabular}{|l|c|c|}
\hline Zone & Number of Violations & $k$ \\
\hline Green & 0 to 4 & 0.00 \\
\hline Yellow & 5 & 0.40 \\
& 6 & 0.50 \\
& 7 & 0.65 \\
& 9 & 0.75 \\
& $10+$ & 0.85 \\
\hline Red & 9.00 \\
\hline Note: The number of violations is given for 250 \\
business days.
\end{tabular}

Note: The penalty structure under the Basel II Accord is specified for the number of penalties and not their magnitude, either individually or cumulatively. 


\section{(C1) Understand the Basel II Colours}

Green means go (away), red means stop (now), and yellow is left to the discretion of the investor. The penalties arising from individual and accumulated violations should be understood in order to make informed decisions regarding whether or not to violate on any given day. The penalty structure is given, but the investor can choose which penalty is optimal on any given day.

\section{(C2) Understand the Risk Model before Choosing}

There are many risk models, depending on the data frequency used. Conditional volatility is most often used to estimate market risk, especially for daily data, but this choice probably arises from historical expediency rather than model superiority. Riskmetrics (1996) seems to be the industry standard. Helpful reviews of the conditional volatility literature are given in Li, Ling and McAleer (2002) and McAleer (2005), while recent reviews of stochastic volatility and realized volatility models are given in Asai, McAleer and Yu (2006) and McAleer and Medeiros (2008), respectively. Understanding the choice of model, especially by appreciating what each model can and cannot do, will make investment decisions more meaningful.

\section{(C3) Vary the Choice of Risk Model}

Be willing to change the risk model that is used to forecast VaR on a daily basis. No risk model dominates all others at all times, and hence no single risk model will minimize daily capital charges on a daily basis. A judicious choice among alternative risk models can and will lead to lower daily capital charges, bearing in mind the penalties imposed for an excessive number of violations.

\section{(C4) Avoid the Green Zone and Be Willing to Violate}

Green may be necessary for a healthy planet, but it is far from optimal for managing VaR. The green zone is both a reward (in terms of $k$ ) for few violations, but there will be few violations when $\mathrm{VaR}$ forecasts are too conservative (meaning too high in 
absolute terms). Stay away from the green zone because the daily capital charges will be too high (for further details, see McAleer and da Veiga (2008a, 2008b)).

\section{(C5) Incur Large Violations}

The Basel II Accord does not penalize excessively large violations, as the penalty structure is intended only for too many violations. If an investor is going to violate, then the violation should be serious (meaning huge). There is no purpose in increasing $k$ if the associated VaR is not being decreased more than proportionately, given the Basel II penalty structure.

\section{(C6) Stop Before the Red Zone}

Avoid the red zone as this can lead to serious penalties, including temporary or permanent suspension. Entering the red zone arises through having accumulated penalties for an excessive number of violations. Although this may mean that VaR is relatively low, the size of violations can also be small, in which case the daily capital charges may not be small.

\section{(C7) Avoid Frequent Violations}

The Basel II Accord penalty structure is intended to punish an excessively frequent number of violations. Therefore, a combination of one or more risk models that do not accumulate an excessively large number of violations should be considered. In seeking to minimize daily capital charges, it is preferable to combine a few violations of large magnitude than a large number of violations of small magnitude.

\section{(C8) Avoid Estimating Large Portfolios}

Large portfolios may be unavoidable in terms of balancing specialization and hedging strategies, but they have too many covariances and/or correlations for purposes of estimation. For example, a 10 asset portfolio has 10 variances and 45 covariances, whereas a 100 asset portfolio has 100 variances and 4950 covariances (see Caporin and 
McAleer (2009a) for possible remedies). In this sense, it may be useful to impose parametric restrictions and to calibrate the model (as in Riskmetrics (1996)).

\section{(C9) Aggregate Portfolios into a Single Index}

Stock market indexes summarize the capitalization of leading financial assets, and are also easy to understand as a single data series. Moreover, a single index requires the specification and estimation of a single risk model, and hence does not have any covariances to estimate. For these reasons, it is sensible to aggregate any given portfolio into a single index and to calculate the VaR accordingly (see, for example, McAleer and da Veiga (2008a, 2008b)).

\section{(C10) Interpret Commandments Sensibly as Guidelines}

The concept of VaR is intended to capture possibly bad outcomes on a typical day, and not when market panic sets in. Investors should be especially careful to interpret these recommendations judiciously when financial markets are in free fall. Sometimes cash is the optimal financial asset, especially when markets are diving and volatility is excessively high.

\section{Conclusion}

Jack Sparrow: [after Will draws his sword] "Put it away, son. It's not worth you getting beat again."

Will Turner: "You didn’t beat me. You ignored the rules of engagement. In a fair fight, I'd kill you.”

Jack Sparrow: "That's not much incentive for me to fight fair, then, is it?" Pirates of the Caribbean: Curse of the Black Pearl

Although commandments are widely read, as confirmed by reference to SSRN views and download statistics, together with laws, rules, regulations, agreements, directives, prescriptions, recommendations, guidelines and codes, commandments are made to be broken, if not altogether ignored. In any matters related to dealing with financial markets, this can be a costly omission, regardless of whether markets are fair or not (for further details, see McAleer (2009) and Caporin and McAleer (2009b)). 


\section{References}

Asai, M., M. McAleer and J. Yu (2006), Multivariate stochastic volatility: a review, Econometric Reviews, 25, 145-175.

Basel Committee on Banking Supervision, (1988), International Convergence of Capital Measurement and Capital Standards, BIS, Basel, Switzerland.

Basel Committee on Banking Supervision, (1995), An Internal Model-Based Approach to Market Risk Capital Requirements, BIS, Basel, Switzerland.

Basel Committee on Banking Supervision, (1996), Supervisory Framework for the Use of "Backtesting" in Conjunction with the Internal Model-Based Approach to Market Risk Capital Requirements, BIS, Basel, Switzerland.

Caporin, M. and M. McAleer (2009a), Do we really need both BEKK and DCC? A tale of two covariance models, Department of Economics, University of Padova (Available at SSRN: http://ssrn.com/abstract=1338190).

Caporin, M. and M. McAleer (2009b), The Ten Commandments for managing investments, to appear in Journal of Economic Surveys (Available at SSRN: http://ssrn.com/abstract=1342265).

Jorion, P. (2000), Value at Risk: The New Benchmark for Managing Financial Risk, McGraw-Hill, New York.

Li, W.K., S. Ling and M. McAleer (2002), Recent theoretical results for time series models with GARCH errors, Journal of Economic Surveys, 16, 245-269. Reprinted in M. McAleer and L. Oxley (eds.), Contributions to Financial Econometrics: Theoretical and Practical Issues, Blackwell, Oxford, 2002, pp. 933.

McAleer, M. (2005), Automated inference and learning in modeling financial volatility, Econometric Theory, 21, 232-261.

McAleer, M. (2009), The Ten Commandments for optimizing value-at-risk and daily capital charges, to appear in Journal of Economic Surveys (Available at SSRN: http://ssrn.com/abstract $=1354686$ ).

McAleer, M., J.-Á. Jiménez-Martin and T. Pérez-Amaral (2009), A decision rule to minimize daily capital charges in forecasting value-at-risk, Department of Quantitative Economics, Complutense University of Madrid, Spain (Available at SSRN: http://ssrn.com/abstract=1349844). 
McAleer. M. and M.C. Medeiros (2008a), Realized volatility: a review, Econometric Reviews, 27, 10-45.

McAleer, M. and B. da Veiga (2008a), Forecasting value-at-risk with a parsimonious portfolio spillover GARCH (PS-GARCH) model, Journal of Forecasting, 27, 119.

McAleer, M. and B. da Veiga (2008b), Single index and portfolio models for forecasting value-at-risk thresholds, Journal of Forecasting, 27, 217-235.

Riskmetrics $^{\mathrm{TM}}$ (1996), J.P. Morgan Technical Document, $4^{\text {th }}$ Edition, New York, J.P. Morgan. 